\title{
Working and Learning in Times of Uncertainty
}

\section{Challenges to Adult, Professional and Vocational Education}

Sandra Bohlinger, Ulrika Haake, Christian Helms Jørgensen, Hanna Toiviainen and Andreas Wallo (Eds.)

Sense Publishers

[ESSELA 
Working and Learning in Times of Uncertainty 


\title{
RESEARCH ON THE EDUCATION AND LEARNING OF ADULTS
}

\author{
VOLUME 4
}

\section{Series Editors}

(On behalf of the European Society for Research on the Education of Adults)

Emilio Lucio-Villegas (University of Seville, Spain)

Barbara Merrill (University of Warwick, United Kingdom)

Marcella Milana (Aarhus University, Denmark)

Henning Salling Olesen (Roskilde University, Denmark)

\section{Scope}

'Research on the Education and Learning of Adults' aims at providing an in-depth insight on the diversity of current research on adult education in diverse teaching/learning contexts in both geographical and cultural terms in Europe. Research on adult education has been characterised by different intellectual traditions, theoretical and methodological approaches and which are still alive today in Europe from the north to the south and from the west to the east. This book series is edited by the European Society for Research on the Education of Adults (ESREA). The content of the series reflects the wide range of research activities undertaken by ESREA's members and networks such as: access, learning careers and identities; active citizenship; the professional development of adult educators; working life; the history of adult education; gender; local development and adult learning; ethnicity; older learners; adult education policies and biographical research. This book series will appeal to an international audience as it engages with current and relevant empirical research, a range of theoretical perspectives and knowledge thus stimulating debate, discussion and knowledge dissemination in the field in a democratic and heterogeneous way.

\section{Editorial Advisory Board}

Michal Bron Jr. (Södertörn University College, Sweden)

Anja Heikkinen (University of Tampere, Finland)

Françoise F. Laot (University Paris-Descartes, France)

Linda Morrice (University of Sussex, United Kingdom)

Joanna Ostrouch-Kamińska (University of Warmia and Mazury, Poland)

Angela Pilch-Ortega (Graz University, Austria)

Andreas Wallo (Linköping University, Sweden)

Georgios Zarifis (Aristotle University of Thessaloniki, Greece) 


\section{Working and Learning in Times of Uncertainty}

Challenges to Adult, Professional and Vocational Education

Edited by

Sandra Bohlinger

Dresden University of Technology, Germany

Ulrika Haake

Umeå University, Sweden

Christian Helms Jørgensen

Roskilde University, Denmark

Hanna Toiviainen

University of Helsinki, Finland

and

Andreas Wallo

Linköping University, Sweden

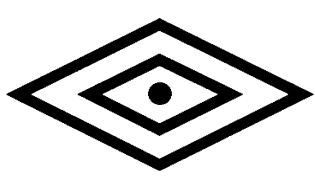


A C.I.P. record for this book is available from the Library of Congress.

ISBN 978-94-6300-242-4 (paperback)

ISBN 978-94-6300-243-1 (hardback)

ISBN 978-94-6300-244-8 (e-book)

Published by: Sense Publishers,

P.O. Box 21858,

3001 AW Rotterdam,

The Netherlands

https://www.sensepublishers.com/

Printed on acid-free paper

All rights reserved @ 2015 Sense Publishers

No part of this work may be reproduced, stored in a retrieval system, or transmitted in any form or by any means, electronic, mechanical, photocopying, microfilming, recording or otherwise, without written permission from the Publisher, with the exception of any material supplied specifically for the purpose of being entered and executed on a computer system, for exclusive use by the purchaser of the work. 



\section{RECOGNITION OF PRIOR LEARNING WITHIN ELDERLY CARE WORK ${ }^{1}$}

\section{INTRODUCTION}

In the last two decades recognition of prior learning (RPL) has emerged as a widespread practice as well as field of research around the world (cf. Evans, 2000; Andersson \& Harris, 2006; Harris et al., 2011, 2014; Andersson et al., 2013). Generally, RPL signifies practices where people have their prior learning and experiences - from work and from other contexts - identified, assessed, and documented, normally through formal credentials. A basic argument in the literature is that RPL is a beneficial tool to increase the employability of citizens at a relatively low cost. This would be beneficial for society, who will have to pay less social benefits etc. to unemployed people, as well as beneficial for the individual, who would be able to find a job and support her/himself. That is, formal credentials that correspond to the individual's prior learning and current, actual competence are seen as crucial for mobility. This is particularly the case in times of uncertainty when it is no longer possible to rely on informal recognition from one single employer, but when the individual has to prepare for mobility between work places, for example through getting credentials that could allow recognition from a new employer.

The history of RPL is long and diverse (Evans, 2000), e.g. with a long tradition in France of experiential learning as the basis for credits and degrees, and efforts in the US after World War II of valuing experiences of war veterans to help them reenter the civil labour market. The more recent history goes back to the early 1970s (see e.g. Michelson, 1996), when 'prior learning assessment' was introduced in the US in an effort to broaden access to higher education. Most RPL initiatives have one or more of the following aims: (i) social justice (in relation to individual opportunities, broader access to education, etc., such as in the example from the 1970s), (ii) economic development (making it possible to use existing vocational/professional competence more effectively in the labour market, an idea developed in several locations, for example, in the UK where RPL was introduced in the 1980s), or (iii) social change (making the actual competence of the population visible creates better conditions for changing society; this is an idea mainly promoted in post-apartheid South Africa, starting in the 1990s) (Andersson et al., 2003).

The case discussed here is an in-service training process in the elderly-care sector in which recognition of prior learning was said to be a central component, 
but nevertheless one component among many others. One central component of the process was of course the new learning that would take place through the in-service training, new learning that ideally would build upon and integrate with participants' prior learning. Typically, earlier in-service training programmes in this context did not seem to have taken the participants' prior learning into account when choosing what and how to teach and study. In-service training was often reported by the employees (i.e. care workers) to repeat what they already knew and, therefore, they found it uninteresting and un-engaging. It often took the form of lectures - one-way communication - and was fragmented. In the studied project, we identified an ambition to engage in a holistic approach to in-service training, an approach where prior learning was assessed and then complemented with educational activities leading to additional new learning, and formal credentials. Furthermore, the process was clearly integrated with the care-workers' workplaces. The manager and a supervisor (one of the assistant nurses) in each unit collaborated with an educational provider. Consequently, the starting point in the design of the process was shaped by the idea that workplace experience is important in relation to formal educational requirements. That is, the educational provider and the employer worked closely together on planning and carrying out the in-service training programme, and care-workers' experiences gained through the years within the occupation were acknowledged and given credit in relation to formal educational requirements. Thus, this project provides an interesting empirical example from which questions of experience, learning, and recognition can be problematised.

The chapter is based on a study of parts of a large governmental project in Sweden called 'Steps for skills' aimed at supporting the municipalities in their work to improve quality and in-service training in the care sector (health care and social care) for elderly people (Step for skills, 2007). The reason for initiating this project was related to the demographic situation in Sweden where the elderly population is increasing and interest in becoming an assistant nurse is decreasing. However, according to the committee for the project, the greatest problem was that people working in the care sector do not have the 'correct' educational background. They often have a diploma from upper secondary school, but not from the healthcare programme. Here, it should be noted that in the care sector, formal credentials and diplomas are important as part of the quality system. The requirements are strict concerning doctors, nurses, and assistant nurses, and demand is growing, at least in the Swedish context, that care workers should be licenced assistant nurses.

The aim of this chapter is to discuss in what ways recognition of prior learning and prior experiences exists as part of the process of in-service training, and whether new learning is an aspect of this process. To understand these concerns, 26 semi-structured interviews (Kvale, 1996) were undertaken with a total of 30 care workers, assistant nurses (some of them acting as supervisors of participating care workers), local managers, and teachers. The aim of the interviews was to see how the informants perceived their participation and work within the in-service training programme. Altogether, 14 participants, six local managers, five supervisors, and five teachers were interviewed. All the interviewees were female. Some of them 
were interviewed twice (two managers, two supervisors, and three participants), at the beginning of the process and four months after the process had ended. Twenty interviews were individual, and six were group interviews, with two to five care workers in each interview. The selection of interviewees was based on the nursing homes participating in the project in one specific municipality, which was chosen because it had made rapid progress with the project. We covered the entire project in this specific municipality so that we could develop a broad and deep understanding of the project.

The analysis of interviews has been conducted using a qualitative interpretative approach focusing on discerning categories related to how the in-service training in the project was perceived by the interviewees regarding the role of experience, learning, and recognition. Firstly, we discuss the way the process of in-service training was organised and how prior learning was assessed. Secondly, we try to discern what role is ascribed to prior learning in the process of training/learning. Thirdly, we problematise the relation between experience, learning, and recognition.

\section{ORGANISING IN-SERVICE TRAINING BASED ON RPL}

The six nursing homes participating in this project were organised into three groups, with one privately owned and one municipally owned nursing home in each. Each group also consisted of an educational provider which had the task of carrying out the process of in-service training based on the health-care programme and on recognising participants' prior learning. The process was carried out using two different modes of organisation. At three nursing homes, the participants worked every second week as usual, without any interruptions from the recognition and training process, and during the other weeks they went to the school that was carrying out the RPL/training process. At two nursing homes, the participants participated in the process for one day a week. In the first week they were engaged in self-study for one day, and they were also guided by their supervisor, an assistant nurse from the nursing home. In the second week, the teacher visited them on one day and gave lectures and conducted discussions to establish the extent of their prior learning. The process in which the participants at these five nursing homes participated was planned to take approximately seven months to one year to finish (compared to one and a half years to finish the programme if one studies full time in the 'traditional' programme as an adult). After this, all the participants were expected to receive a degree from the health-care programme, and thus be able to be employed as assistant nurses.

However, at the sixth nursing home, all the employees were already assistant nurses. Thus, here they chose to organise a process of recognising prior learning in relation to the course of ethics in the health-care programme, as that course had been extended in terms of content (and credits) compared to the same course a few years ago when these employees received their degrees.

As a way of conducting these processes of RPL, the participants at the different nursing homes were involved in activities that could be related to both a process of education and teaching and to a process of recognition and assessment of prior 
learning. Teaching was conducted by a teacher who gave short lectures related to the module to be assessed. Furthermore, the participants had to discuss cases among themselves, and also to discuss these cases with their supervisors in 'learning conversations'. In these learning conversations the supervisor brought an issue or a case into the discussion, and the participants were encouraged to reflect on the issues discussed while the supervisor guided the conversation so as to involve everyone.

Assessment, including RPL, was carried out by teachers from the three educational providers. Generally, the assessment of the participant's knowledge was made by means of discussions and written assessments. A central component was the use of cases that the participants had to discuss, both orally and in writing. The aim of the assessment was to discover firstly what the participants already knew in relation to the health-care programme, and, secondly, what parts of the programme they needed to study more - by reading and doing assignments.

We can see how in-service training based on RPL in this case is a collective and individual process of teaching, assessment, and learning. On the one hand, the participants participate in a collective learning process based on discussions relating to prior experiences. Furthermore, their learning is based on short lectures by the teacher, and on reading books and doing oral and written assignments. On the other hand, their prior learning is assessed, although it is hard to distinguish exactly to what extent knowledge based on prior learning is being assessed, and to what extent it is the result of new learning (partly based on prior experiences). In the following sections, we will illustrate in greater detail what role prior learning has in the process of recognition of prior learning, and describe the relation between experience and learning that is constructed.

\section{THE ROLE OF PRIOR LEARNING}

In the next section, we will analyse the role of prior learning in the process of inservice training in which RPL was an integrated part. We identified three areas as specifically characterising this process. These areas seemed to interact in the construction of prior learning as a central part of the process, and therefore we wanted to analyse them further. The three areas were: the individual's prior knowledge acting as a starting point, discussion as a main working form, and production of new knowledge.

\section{The Individual's Prior Knowledge as a Starting Point}

A prominent feature of the process of recognition of prior learning is the actual focus on participants' prior learning and knowledge. That is, the results indicate how recognising prior learning is not only part of the project's rhetoric, but also a central aspect of the actual process. As one local manager expressed it: 'the focus is on ... how the specific individual's learning looks like and how that individual apprehends him/herself' (Manager 9). The process concentrates on what the individual needs (in relation to the individual background as well as certain 
criteria), instead of on what someone else decides that they have to study. As a supervisor expressed it when she spoke about this process:

Here, the way they learn makes them say: "But we know that". And then the teacher knows - I don't need to waste any time on that. Here, we can focus on what we need. That's the difference I believe. (Manager 9)

What is apparent is the focus on individuals and their prior experiences, learning and knowledge - that is, on what an individual knows, which is the starting point for developing his/her competencies. The informants seem to be well aware of the idea of recognising prior learning, as a basis for the project that is also enacted in practice. One participant compared the process to regular schooling:

Here, you really find out about the experiences, what you have. And then you can, so to speak, speed up the pace of an educational programme, you don't need to drag it out over time. In a regular educational programme you need to read through everything. And also do these usual assessment tasks or in other ways show what you know. So for me, this process of recognition of prior learning was really good as you didn't need to read so much. Instead, you can acknowledge what you already know. (Participant 1)

For this participant, the training highlighted her experiences and what she already knew. The idea of estimating one's own knowledge before the teacher designs and carries out the RPL process supports such an interpretation. Participants from two nursing homes described how they were encouraged to make a self-assessment, to estimate their own knowledge in a certain area before the teacher planned how to assess their knowledge, and how to design each module. Thus, the individual's prior experience, learning and knowledge are the starting points for the RPL process.

\section{Discussion as a Main Working Form}

The emphasis on the participant's prior learning and experiences can also be seen in relation to the main working form in this project. Instead of the one-way communication that often seemed to be the norm in regular in-service training at the nursing homes analysed, the focus here was on two-way communication by means of discussion. Almost all the interviewees described how discussions are an important part of recognising the participant's knowledge. Through the discussion, the participants make visible what they already know, which is then assessed by the teacher. But the discussion also means that they are exposed to what others know, something which should be reflected upon in the discussion. Thus, there is also the potential for new learning to take place, as two participants said in an exchange of words:

All the discussions we can have here, and everyone has experiences, and the exchange there. It's not possible to compare with anything else. (Participant 13) 


\section{A. FEJES \& P. ANDERSSON}

It brings together the group that we are, I believe. This is great, you get to know each other. And you view each other in new ways than was previously the case, even if we have worked together for 15 years. You find new good points in the others which you hadn't seen before. And you help each other and ... Yes, this is great. (Participant 12)

Here, we can see a relation constructed between experience, reflection and learning. By discussing certain issues, participants' experiences are reflected upon, which results in new ways of perceiving each other. RPL in this form can thus be seen as both an individual and a collective process of learning in which participants increase their participation in a specific community related to their own nursing homes where they learn from each other's experiences.

By using discussion as the main working method, the participants are encouraged and 'forced' to be active. Thus, there is an emphasis on dialogue and two-way communication as a means of recognising learning and enabling learning to take place, which puts pressure on participants to be active. As two interviewees express this in the following exchange of words:

Now it's about grades, which in some way feels a bit more serious. (Participant 8)

Yeah. Now we could say ... we go to school, yeah, so really that's what we do. And it feels a bit more that one has ... to learn more than in a lecture on how to treat a wound. Of course that's also useful, but it's not...there we haven't been given a task or anything. Here we have a task, therefore one needs to be alert and...it's not enough to just sit here and let the time go by. (Participant 7)

Here, we can see how the work forms used require the participant to be active. The discussions are designed as a way of making everyone active. Having grades and assessment tasks makes the participants feel that this process is more serious than only participating in a lecture every now and then, which is the common format of in-service training at these nursing homes.

However, some of the participants would have preferred more regular schooling where someone lectures. They were probably more used to having someone tell them what is correct or incorrect, as often seemed to be the case in regular inservice training, and they get frustrated when they are the ones to find the solutions. We can find a similar result in Ellström and Ekholm's (2001) study of care workers in the same sector as in our study. According to them, the care workers at one unit were sceptical about a course on quality in care work, in which discussions were the main work form. They had only a vague perception of what the course was about, thus they were hesitant to describe what effects it had. Such problems and frustrations raised by the interviewees are something that can occur when students encounter knowledge that has previously been denied them (or not been available in the contexts they have been active in). Thus, the teacher needs to be able to handle such anxiety (Giroux, 1988). According to Freire (Shor \& Freire, 1987), it is not an easy task to help the students to develop the knowledge that has 
previously been denied them, and the teacher needs to support the students by giving examples through action. However, in our case the focus was on participants' learning from reflection on a problem - problem-solving without any major interference from the teacher.

It follows that discussion as a main working form captures prior learning as an important aspect of the RPL process. Moreover, teachers need to be able to handle the students' anxiety when they encounter knowledge which has previously been denied them. In the next section, we will argue that this process of recognition of prior learning, besides assessing prior learning, also produces new knowledge.

\section{Production of New Knowledge}

Many of the respondents said that the process based on RPL is more substantive than regular in-service training and thus creates a clearer structure. Instead of small pieces every now and then (as claimed in the case of regular in-service training), there is a clear, comprehensive process, which the participant follows. Furthermore, several of the local managers discussed the importance of having a long-term plan for how to create a good in-service training process. One of the managers defined this kind of in-service training as production of knowledge, instead of consumption.

What happens after February [when the program ends]? Will we return to our usual consumption of knowledge ... competence consumption in which we buy something, and that's really good so we show it to others? How can we produce this knowledge here, and make it clear. I think that in some way one can - with guidance, with these techniques, create those moments of reflection, which we often lack. (Manager 6)

Thus, RPL and the method of learning conversations and reflection are seen as things that make the participants produce instead of consume knowledge. We could say that a relation is construed between work experience, reflection, and learning. We have the experiences of all the care workers, and reflecting on them results in production of new knowledge (i.e. new learning).

Thus, the participant's prior learning and experiences are seen as important parts of the recognition process. A relation is also established between experience, learning and recognition, something that will be elaborated on in greater detail in the next section.

\section{Experience and Learning}

Our main interest in this section is the relation between experience, learning, and recognition. The initiative aimed to give recognition to prior learning and to develop new learning through educational activities. However, there is also learning that takes place in the process of assessing prior learning, something which is not accounted for in the interviews, or in prior research on RPL. 


\section{A. FEJES \& P. ANDERSSON}

From constructivist perspectives such as Kolb's (1984), learning is the result of reflected experiences. In this project, the recognition process was to a large extent based on reflection, and such a process is also a process of learning. The participants had much experience from working in elderly care. This experience probably resulted in learning, particularly in instrumental learning, in which they learnt how to do different things in the workplace. One central aspect of the recognition process is that the participants showed that they could do these things, and they got recognition for this. A supervisor emphasised the importance of experience in this specific vocation. She argued that that is what counts, and education is only a complement.

Yes, it's experiential knowledge. We have a lot of that knowledge here ... this work we are doing here, it's experience that counts. That's how it is. And then, education is a complement. (Supervisor 1)

Such experience probably sometimes turned into learning but not always. This latter issue can be related to another aspect, namely, what happens when care workers solve tasks and participate in reflective discussions in the learning conversations? It turns out that the participants had not been used to reflecting on and discussing their work and what they do. Thus the tasks and the conversations not only mean that they made visible what they had learnt previously and got recognition for it, but also that they might turn their prior experiences into knowledge through the learning process of conversation and reflection. In this way, prior learning is a part of the process of in-service training, where it both gets recognition and is a starting point for new learning. But when it comes to prior experience (that has not yet resulted in learning), it is the other way around. Here, it is new learning that becomes a part of the recognition process. Prior experience forms the basis of reflection that results in knowledge, which can then be afforded recognition.

Accordingly, RPL cannot be seen only as recognising prior learning, but also as recognising learning taking place during the assessment process. So even if we have empirically illustrated that prior learning plays a central role in the process, we must also add the new learning that probably takes place. By new learning, we do not only mean learning taking place in those areas where the participants lack knowledge (e.g. medical knowledge which requires additional teaching), but also learning taking place in the assessment process when one's prior experiences are reflected on and questioned. In another quotation, we can see how, according to a supervisor, such questioning of prior assumptions takes place among the participants:

They recognise a bit more, how should I put it ... to think in another way.

You don't have to continue to have this tunnel vision all the time. They have become a bit ... wider in their ways of thinking. (Supervisor 2)

By reflecting on prior experiences and ways of doing work, you might create new assumptions, or revise/discard your old ones. On another level, we could also reflect on the experience of the recognition process per se. This is a new 
experience for the participants, and if/when they engage in reflection on this process, they will learn something about the process of conversation, reflection, and recognition. It could be both instrumental learning, concerning how to reflect and how to behave in a recognition process, and communicative learning, developing the capacity to reflect on and communicate about the experience of participating in this process.

So, it seems that the process of RPL results in new learning, and this learning is part of what is being assessed. Consequently, it is hard to distinguish between prior and new experiences and learning when assessment is carried out. In the final section, we will discuss how the kind of self-reflective techniques used in this programme can also be seen as developing one's capacity for critical thinking, i.e. new learning that is also assessed in the process.

\section{DISCUSSION}

RPL is about identifying, assessing, and documenting a person's prior learning no matter where learning has taken place. In this chapter we have analysed an inservice training programme where care workers' prior learning has been assessed in relation to the health-care programme. The process of recognition of prior learning has been carried out in close relationship between the workplace and an educational provider. Assessment of prior learning has been integrated with additional educational activities. Our aim has been to understand in what ways recognition of prior learning and prior experiences is part of this process of inservice training, and how new learning is an aspect of the process. Thereby, we problematise the relation between experiences, learning, and recognition. In this last section we will particularly discuss the relation between prior and new learning in a training process where the recognition of prior learning is expected to play a significant role. Here, we also highlight issues of power as important matters to discuss.

As the findings illustrate, the participants in the project had much experience from all their years working as care workers. According to the teachers carrying out the assessment, it was possible to identify and assess these experiences in the process of recognition of prior learning. In relation to some of the courses, such assessment has been possible merely by having a couple of group discussions with the participants. Thus, the participants are constructed as people who have prior experience, which also means that they have certain knowledge that can be 'ticked off' on the list of courses, or part of courses, and then added to by means of new learning. However, we have argued that the new learning is not only constructed through the educational processes following the recognition process, but also, through the lens of a constructivist perspective on learning, the recognition process probably produces new learning, which is included in what is being assessed. As found in a study reported by Scott (2007), those with prior experiences from the area might perceive learning even if they already have the relevant knowledge. This must not only be understood in terms of developing different knowledge through practical experience and through an educational process, it must also be 
area might perceive learning even if they already have the relevant knowledge. This must not only be understood in terms of developing different knowledge through practical experience and through an educational process, it must also be understood in terms of learning from experience in the educational process. That is, the reason why the perceived learning among those with experience is higher than expected could be that their experience makes it possible for them to learn more through reflection upon this experience - than those without experience.

From the findings here, it seems that the discussion about RPL needs to include an understanding about what the recognition/assessment process in itself produces. It not only produces a documentation/grade/credential or the ticking off of a course, but it also gives the opportunity for new learning (e.g. the development of care workers' ability to think critically). These issues have, as we illustrated in our overview of previous research, often been neglected. Placing an emphasis on the participants' prior learning and experiences, and using these in the learning and assessment process, is something that could also be beneficial in regular educational activities. In one way, the in-service training presented in this chapter could be seen as adapting 'classical' pedagogical ideals promoted in adult learning theory (cf. Brookfield, 1987; Knowles, 1989; Mezirow, 1991). However, such processes are not without problems. The teacher needs to acknowledge the students' anxiety and frustration when they encounter knowledge that has previously not been available to them (Shor \& Freire, 1987; Giroux, 1988). Thus, it is important to recognise issues of power in such a political practice as care work.

Consequently, issues of power are an important complement to the constructivist theories of learning upon which we base the major part of our analysis. This fact is important as constructivist theories of learning neglect issues of power. For example, Michelson (1996) argues that a focus on reflection about experience is dualistic (body/mind) and that it disregards relations of power. She points to how the process of prior learning assessment makes the body invisible, with reflection and experience being seen as two separate processes - i.e. the reflection of the mind is in the foreground and the bodily experience invisibly present in the background. Similarly, Fenwick (2003) holds that experience and the knowledge-making process (reflection) are construed as two separate elements. She says: 'reflection itself is experienced, and experience as event cannot be separated from our imaginative interpretation and re-interpretation of the event' (ibid., p. 126). Thus, she argues that one cannot separate experience from reflection and knowledge.

We can to some extent agree with this critique since experience, reflection, learning, and knowledge cannot be truly separated - all aspects of the lived experience are integrated in the process of real life. However, different perspectives on experience, learning, and knowledge help us understand different aspects of a process of recognising prior learning. We have employed a constructivist perspective to identify certain aspects of such a process. Our analysis shows how 'classical' ideas of adult education are enacted. Experience, prior learning and new learning interact in a way that is not always the case in the practice of adult education. This and other studies focusing on integrated RPL 
important, not least in times of uncertainty. Credentials and diplomas are part of the formal system that makes mobility and employability easier - particularly in a sector like health care where formal qualifications are central to the system to ensure quality, and the requirements to be employable are strict.

\section{NOTE}

1 This chapter is a revised version of an article by Fejes and Andersson (2009), published in Vocations and Learning, 2(1), 37-55.

\section{REFERENCES}

Andersson, P., Fejes, A., \& Sandberg, F. (2013). Introducing research on recognition of prior learning. International Journal of Lifelong Education, 32(4), 405-411.

Andersson, P., \& Harris, J. (Eds.) (2006). Re-theorising the Recognition of Prior Learning. Leicester: NIACE.

Andersson, P., Sjösten, N.-Å., \& Ahn, S.-E. (2003). Att värdera kunskap, erfarenhet och kompetens: Perspektiv på validering. Stockholm: Myndigheten för skolutveckling.

Brookfield, S. D. (1987). Developing critical thinkers: Challenging adults to explore alternative ways of thinking and acting. San Francisco, CA: Jossey-Bass.

Ellström, E., \& Ekholm, B. (2001). Lärande $i$ omsorgsarbete: En studie av hemtjänsten som lärandemiljö. Linköping: Linköping University, CMTO research monographs, NO 1.

Evans, N. (Ed.). (2000). Experiential learning around the world: Employability and the global economy. London: Jessica Kingsley.

Fejes, A., \& Andersson, P. (2009). Recognising prior learning: Understanding the relations among experience, learning and recognition from a constructivist perspective. Vocations and Learning, 2(1), 37-55.

Fenwick, T. (2003). Reclaiming and re-embodying experiential learning through complexity science. Studies in the Education of Adults, 35(2), 123-141.

Giroux, H. A. (1988). Teachers as intellectuals: Toward a critical pedagogy of learning. Massachusetts: Bergin \& Garvey.

Harris, J., Breier, M., \& Wihak, C. (Eds.). (2011). Researching the recognition of prior learning: International perspectives. Leicester: NIACE.

Harris, J., Wihak, C., \& van Kleef, J. (Eds.). (2014). Handbook of the recognition of prior learning: Research into Practice. Leicester: NIACE.

Kolb, D. (1984). Experiential learning: Experience as the source of learning and development. Englewood Cliffs: Prentice-Hall.

Kvale, S. (1996). Interviews: An introduction to qualitative research interviewing. Thousand Oaks, CA: Sage.

Knowles, M. (1989). The making of an adult educator. San Francisco, CA: Jossey-Bass.

Mezirow, J. (1991). Transformative dimensions of adult learning. San Francisco, CA: Jossey-Bass.

Michelson, E. (1996). Beyond Galileo's telescope: Situated knowledge and the assessment of experiential learning. Adult Education Quarterly, 46(4), 185-195.

Scott, I. (2007). Accreditation of prior learning in pre-registration nursing programmes: Throwing the baby out with the bath water? Nurse Education Today, 27(4), 348-356.

Shor, I., \& Freire, P. (1987). A pedagogy for liberation: Dialogues on transforming education. Massachusetts: Bergin \& Garvey.

Somerville, M. (2006). Becoming-worker: vocational training for workers in aged care. Journal of Vocational Education and Training, 54(4), 471-481.

Step for skills. (2007). SOU 2007:88: Att lära nära: Stöd till kommuner för verksamhetsnära kompetensutveckling inom omsorg och vård av äldre. Stockholm: Regeringskansliet. 
FEJES AND ANDERSSON

Andreas Fejes

Department of Behavioural Sciences and Learning

Linköping University, Sweden

Per Andersson

Department of Behavioural Sciences and Learning

Linköping University, Sweden 